who presented papers were R. E. Carter from the General Electric Company, Schenectady, USA, and H. Rickert from the University of Karlsruhe, Germany. Not only were the thermodynamic aspects of the EMF method discussed but also kinetic measurements with solid electrolytes and the practical application to the determination of oxygen in liquid metals, such as silver, copper and iron. T. L. Markin (AERE, Harwell) presented a paper on galvanic cells reversible to fluorine ions.

I am not normally in favour of publication of the proceedings of conferences or other forms of multi-author books. Where, as in the present case, however, the meeting deals with a small, specialized field, two days of discussion can cover the field nearly exhaustively, and one has the impression that it did indeed do so for the subject defined by the title. It should be added that much hard work seems to have gone into the editinga praise one cannot, alas, often express.

The high price obviously reflects the relatively small number of expected purchasers of the book, but for those whose work is somehow related to the subject it will be indispensable.

O. KuBASCHEWSKI

\section{ATOMIC ABSORPTION METHODS}

\section{Atomic-Absorption Spectroscopy and Analysis by Atomic-Absorption Flame Photometry}

By Juan Ramirez-Munoz. Pp. xxi+681. (Elsevier: Amsterdam, London and New York, 1968.) 1958.

The book is divided into five sections. Parts 1 (42 pages) and 2 (68 pages) deal with fundamental theory and instrumental systems. The third part ( 76 pages) discusses the range and limitation of atomic absorption methods and this, together with part 4 (160 pages) on experimental methods, contains nearly all the information necessary for the analyst to determine the optimum conditions and most suitable calibration procedure for any particular problem. This is easily the clearest and most concise account available for practical atomic absorption analysts. Part 5 (42 pages) is a review of the different applications published to December 1967, and deals with the analysis of waters, "agricultural materials" (fertilizers, plants, soils), biological materials (including blood, milk, bones, saliva), rocks and minerals, metallurgical products and $\mathrm{Li}$ and $U$ isotopes. The bibliography contains nearly 1,000 itcms. The book is concerned principally with flame sources as a means of producing atomic vapours, but other approaches such as the L'vov furnace method are mentioned in satisfactory detail. The translation by W. D. Line has preserved the evident clarity of the author's thought, resulting in a thoroughly comprehensive and readable book.

J. R. Butler

\section{ADVANCES IN CIRCUIT THEORY}

\section{Network and Switching Theory}

A NATO Advanced Study Institute. Edited by Giuseppe Biorci. (Electrical Science: A Series of Monographs and Texts.) Pp. xvii +634 . (Academic Press: Now York and London, 1968.) 256s. $8 d$.

ALTHOUGH it is sometimes stated that the existence of computers and the emergence of system theory have made network theory obsolete, this apparently sophisticated appraisal of the situation, in fact, is at the present time only naïve. For although computers are valuable tools for solving particular problems, their use does not absolve the circuit designer from the necessity for possessing a thorough knowledge of network theory. Similarly the adoption of block units in a system study does not obviate the need for a complete understanding of tho circuits which the block units represent. Indeed, network theory is still expanding in both depth and range, as is demonstrated by the work presented at the numerous international conferences which continue to be held on this subject and of which the NATO Advanced Study Institute on Network and Switching Theory, held at Trieste in 1966, is an excellent example. Most of the lectures delivered at this institute are included in the book under review, and many of thom reached a very high standard.

The book contains papers on several fundamental aspects of network theory, and among those the following are particularly noteworthy: the laws of energy distribution in linear and non-linear networks in the papers of Duinker and Adams; the generalization of network structure concepts in the papers by Benzaken and Kuntzmann; and the discussions of state space analysis in the papers of Zadeh and Kuh et al. As in other branches of engineering, theoretical advances in network theory are not infrequently made in response to practical needs and a good example of such a response is the studies that have recently been carried out on networks containing lumped and distributed elements, and an important contribution on this subject is given in Youla's paper.

One notable feature of modern network theory is that the classical theory of linear, lumped passive, time invariant systems does not remain static but is constantly being enlarged by new research. Among the papers contributing to these advances are those discussing single element networks by Buesch and Civalleri and the one on active network design by Spence. Notwork theory is not limited in its application to electrical circuits and good examples of the wider generality and applicability of this subject were shown by several of the papers contributed to this NATO study institute. For example, graph-theoretical properties were discussed by Lempel, Cederbaum and Myers, and combinatorial networks were considered by Meo, Morreale and Minnick.

An important offshoot of network theory is switching theory and, as the title of the conference implies, this aspect was also considered. In this section there were basic papers on switching theory and sequential circuits by Unger, Grasselli, Luccio, Susskind and Gerace.

In conclusion, the various papers included in this volume contain a large amount of new material on network and switching theory which is important to workers in this field and this work should prove valuable to these specialists.

G. S. Brayshaw

\section{MOVEMENTS OF STARS}

\section{Stellar Kinematics}

By W. M. Smart. Pp. vii +320 . (Longmans: London, 1968.) $84 s$.

Professor Smart has written the first book entirely about this subject since Eddington's Stellar Movements appeared in 1914. The ideas which have been introduced in the past fifty years, and the prospect of a marked increase in the observational material during the noxt ten, would both justify the appearance of a new authoritative book.

Because we can measure neither gravitational force nor acceleration in astronomy, stellar dynamics is essentially a theoretical branch of the subject. If it is to have any connexion with stars, it must be through stellar kinematics, and the revival of interest in dynamics should stimulate renewed attention to the analysis of observations. The past exchanges of ideas between theory and observation are evident in Professor Smart's book. With the success of the kinetic theory of gases in the past century, it was reasonable to suggest that the distribution of stellar velocities should be Maxwellian. Statistical studies of proper-motions revcaled, however, that the distribution was not isotropic. The observations suggested either a 